
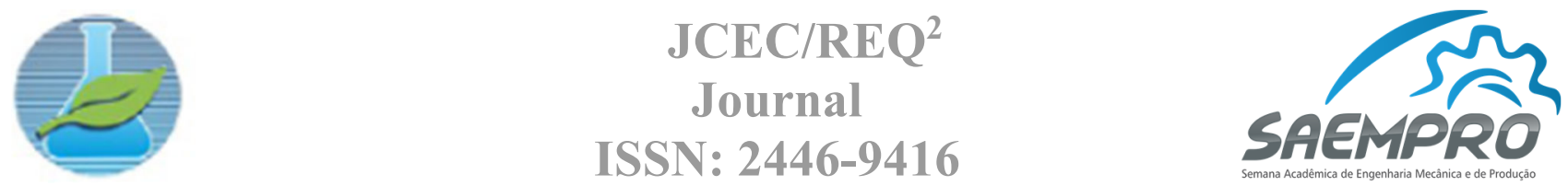

\author{
"EU, A INDÚSTRIA E O MUNDO" \\ 08 a 11 de novembro de 2016 no campus Viçosa da UFV \\ Departamento de Engenharia de Produção e Mecânica - DEP \\ Universidade Federal de Viçosa - UFV
}

\title{
COMPARAÇÃO DO DESEMPENHO DOS PROCESSOS TIG E ELETRODO REVESTIDO NA SOLDAGEM DO FERRO FUNDIDO VERMICULAR
}

\author{
Natália Sodré da Silveira Mol, Charles Luís da Silva \\ Universidade Federal de Viçosa, Departamento de Engenharia de Produção e Engenharia Mecânica \\ Avenida P.H. Rolfs, s/n - 36570000 - Viçosa - MG \\ natsodremol@hotmail.com
}

\section{INTRODUÇÃO}

O ferro fundido em grafita compacta ou vermicular é caracterizado pela grafita em formato de escamas (Chiaverini, 2012). Sua comercialização é nova se comparada com os outros tipos de ferro fundido e seu uso veem crescendo na indústria automobilística abrindo-se as possibilidades de seu emprego em peças como coletores de escapamento, cabeçotes e principalmente blocos de motores diesel (Junior \& Guesser, 2011). Quase todos os processos de soldagem resultam, nas partes que estão sendo unidas, em variações de temperatura e em deformações plásticas. Isto causa alterações na estrutura dos materiais da junta sendo soldada e de suas propriedades (Bracarense et al., 2009). Uma das dificuldades na soldagem de ferros fundidos é sua tendência para formar microestruturas duras e frágeis na ZTA (De Paris, 2003). Outro problema envolvendo a soldagem de ferro fundido está na formação de porosidades na solda. Com a alta temperatura da solda, a grafita fica mais fluida e sai da microestrutura, dissolvendo-se no metal. Este, por sua vez, fica menos fluido, de modo que o vazio deixado não é preenchido, resultando em porosidade (De Paris, 2003).

Diante desses vários problemas, é uma necessidade contínua a busca por métodos que proporcionem uma melhor qualidade da solda em ferro fundido, reduzindo os efeitos negativos descendentes da criação da ZTA, bem como os efeitos diversos que fragilizam a qualidade da solda. As variáveis do processo de soldagem que influenciam diretamente na criação da ZTA foram executadas e estudadas, a fim de buscar uma condição ideal, que configure o melhor processo de solda para ferro fundido o possível.

Neste projeto analisou-se e comparou-se os processos de soldagem TIG e Eletrodo Revestido para soldas do tipo "topo" em placas de Ferro Fundido Vermicular, com o intuito de otimizar os resultados obtidos. Como instrumentos de análise foram realizados estudos metalográficos da região do cordão de solda afim de classificar os cordões quanto ao tipo e a quantidade de defeitos presentes. Observou-se ainda no que se diferem os processos principalmente em relação a qualidade da solda.

\section{METODOLOGIA}

Para o metal base foi utilizada uma barra de ferro vermicular normatizada, a partir da qual foram extraídos filetes de aproximadamente $5 \mathrm{~mm}$ de espessura, destinados a receber os cordões de solda. A soldagem em Eletrodo Revestido e TIG foi feita utilizando polaridade direta. Foram soldados dois corpos de prova para cada corrente de soldagem (70 A, 80 A e 90 A) em cada processo de soldagem. Foi realizado também uma variação do processo de soldagem TIG, em que utiliza um eletrodo sem revestimento como material de deposição. Esta variação é chamada TIG com eletrodo nu e foram soldados um corpo de prova para cada corrente de soldagem (70 A, 80 A e 90 A) nesse processo. 
Após realizada a soldagem, as amostras foram cortadas e embutidas em baquelites para posterior lixamento, ataque químico e análise metalográfica. O processo de lixamento iniciou-se com a lixa 80, percorrendo várias granulometrias, até chegar na 1.200. Tal processo foi realizado aplicando-se pouca pressão nas amostras, com refrigeração a água constante e rotacionando as amostras de $90^{\circ}$ quando houve transição da lixa anterior para a sua subsequente. $O$ passo seguinte foi fazer o polimento nas amostras a fim de eliminar os riscos ainda presentes da última etapa de lixamento (utilizou-se pano para polimento e pequenas quantidades de alumina, de granulometria 0,3 e 0,05 mícrons). $\mathrm{O}$ ataque das amostras polidas foi feito mediante imersão da superfície em solução de ácido nital e água destilada na concentração de $2 \%$ de ácido por aproximadamente 10 segundos. As amostras foram então submetidas a observação em um microscópio óptico do fabricante OLYMPUS, modelo BX51M com lentes de aumento de 50X, 100X, 200X, 500X, 1000X.

\section{RESULTADOS E DISCUSSÃO}

Observando os corpos de prova soldados por eletrodo revestido com corrente de $70 \mathrm{~A}, 80 \mathrm{~A}$ e 90 A; por TIG com corrente de 80 A e por TIG com eletrodo nu com corrente de $70 \mathrm{~A}, 80 \mathrm{~A}$ e $90 \mathrm{~A}$, percebe-se que a região mais próxima da zona fundida apresentou algumas estruturas na forma de agulhas. Pesquisando em artigos científicos, é comumente adotado que estas estruturas são martensitas, resultantes da cristalização da austenita como dentrita primária. Esta cristalização ocorre da seguinte forma: à medida que o material se solidifica, a parte fundida restante se torna cada vez mais rica em carbono, o que resulta na formação de cementita-austenita eutética. Após mais tempo de resfriamento, a porção de austenita se transforma em martensita (Chandra et al., 2014). A martensita é dura e frágil, principalmente quando a quantidade de carbono é alta (Askari-Paykani et al., 2014). Resumindo, a ZTA é constituída de nódulos de grafita, martensita e perlita.

Conclui-se que esses processos de soldagem se evitou problemas de soldagem na zona fundida, porém não na ZTA. O impacto nas propriedades da junta soldada irá depender da concentração e distribuição de martensita na ZTA. Os corpos de prova com corrente de soldagem igual a 70 A trincas e poros na zona fundida. Conclui-se que este processo não evitou problemas de soldagem tanto da zona fundida quanto da ZTA.

Os corpos de prova soldados com corrente igual a 90 A apresentaram uma zona parcialmente fundida. Esta zona é intermediária à zona fundida e a ZTA. A martensita apresenta-se distribuída de forma diferente do que na ZTA. Os impactos nas propriedades da junta soldada irão depender da concentração e distribuição de martensita na ZTA, logo é necessário realizar um teste de microdureza para analisar como estas diferentes distribuições interferem na dureza e fragilidade do metal soldado. As Fig. 1, 2 e 3 ilustram tudo o que foi descrito acima.
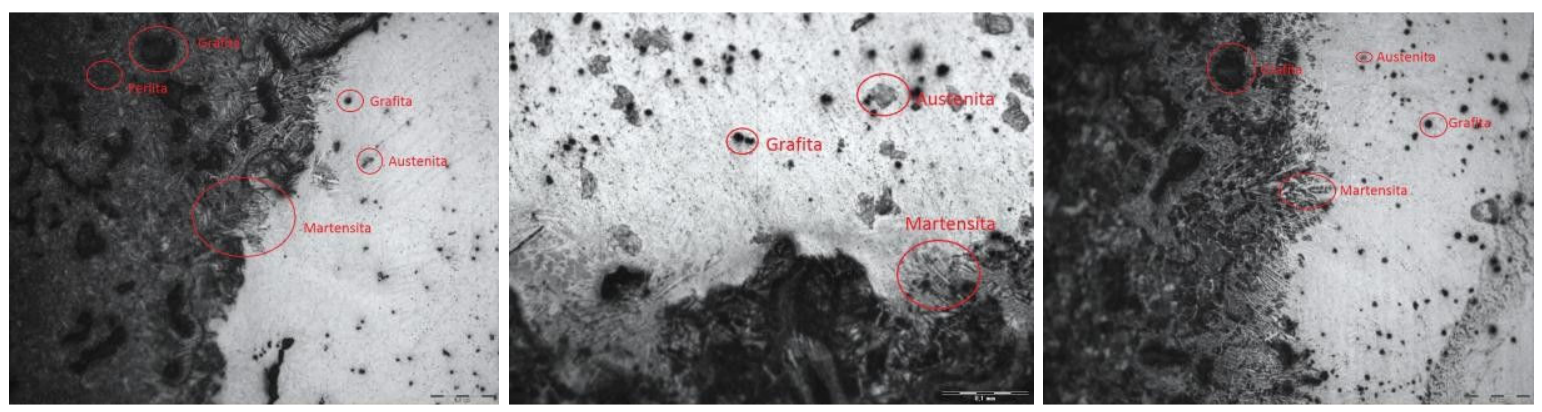

Figura 1 - Zona fundida e ZTA do corpo de prova soldado por eletrodo revestido com corrente de 70A (esquerda) e 80 A (meio) e 90 A (direita). Ataque: Nital 2\%. Imagens obtidas com aumento de 200X. 

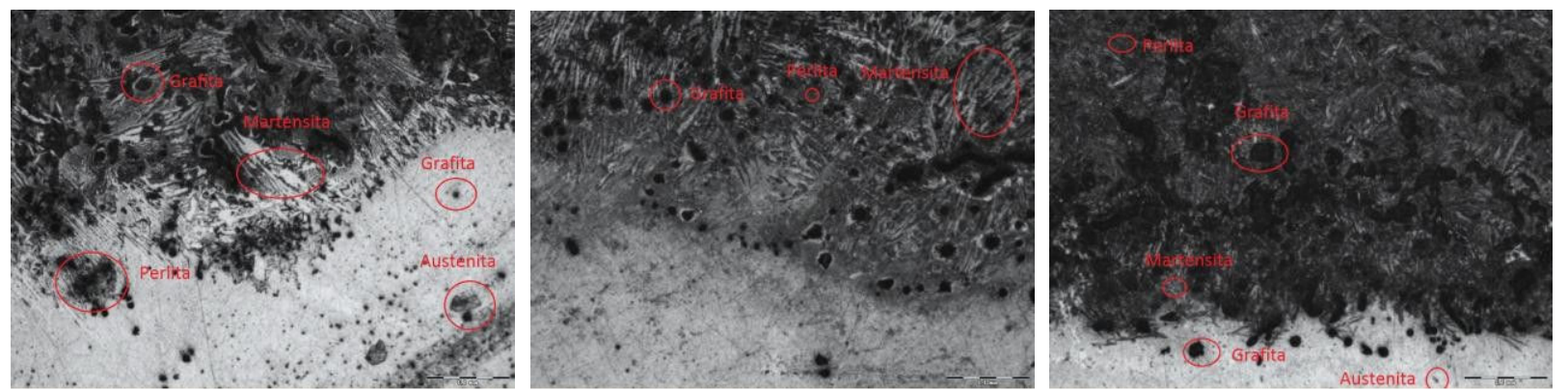

Figura 2 - Zona fundida e ZTA do corpo de prova soldado por TIG com corrente de 80 A (esquerda) e por TIG com eletrodo nu com corrente de 70 A (meio) e 80 A (direita). Ataque: Nital 2\%. Imagens obtidas com aumento de 200x.
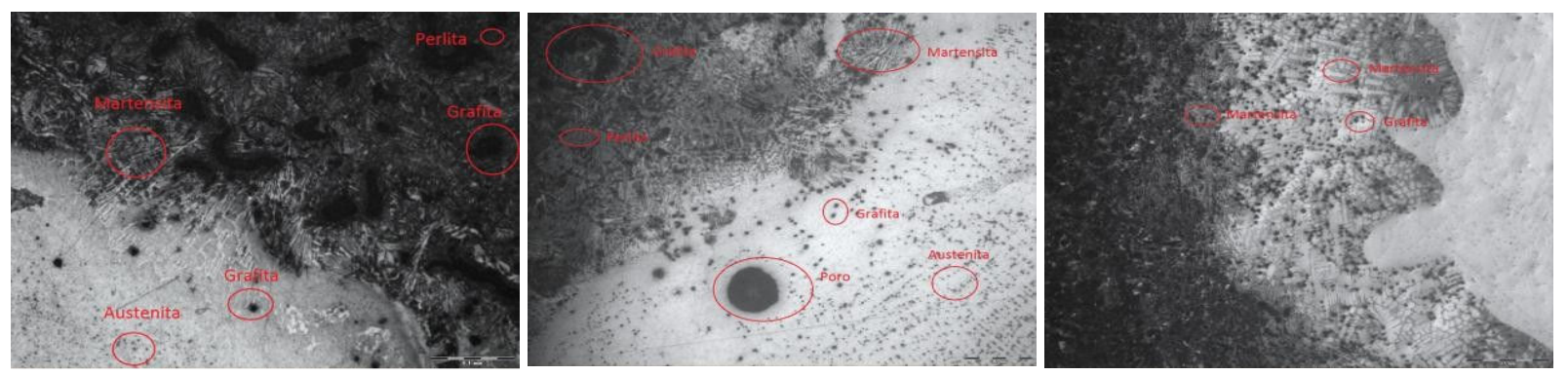

Figura 3 - Zona fundida e ZTA do corpo de prova soldado por TIG com eletrodo nu com corrente de 90 A (esquerda) e por TIG com corrente de 70 A (meio) e 90 A (esquerda). Ataque: Nital 2\%. Imagens obtidas com aumento de 200X (esquerda) e 100X (meio) e 50X (direita).

\section{CONSIDERAÇÕES FINAIS}

Analisando a ZTA, percebe-se que nos corpos de prova soldados, independente do processo de soldagem e corrente, houve uma nodularização incompleta da grafita. A solda que apresentou maior fragilidade foi a realizada pelo processo TIG com corrente de soldagem igual a 70A. Isto ocorreu devido ao aparecimento de trincas e poros na zona fundida. Todos os outros processos de soldagem apresentaram microestrutura parecida, variando apenas a distribuição e concentração de martensita. Sabe-se que a martensita causa o aumento da dureza e da fragilidade da ZTA, que variam de acordo com a concentração e distribuição. Para uma melhor análise da resistência mecânica destes corpos de prova é necessário a realização de um teste de microdureza.

\section{REFERÊNCIAS}

ASKARI-PAYKANI, M.; SHAMANIAN, M.; SHAYAN, M. "Weldability of Ferritic Ductile Cast Iron Using Full Factorial Design of Experiment". Journal of Iron and Steel Research, International, Iran, 2014.

BRACARENSE, A. Q.; MARQUES, P. V.; MODENESI, P. J. "Soldagem: fundamentos e tecnologia". $3^{\text {a }}$ ed. Belo Horizonte: Editora UFMG, p. 494, 2009.

C.-M. LIN; A. S. CHANDRA; L. MORALES-RIVAS; S.-Y. HUANG; H.-C. WU; Y.-E. WU; H.L. TSAI. "Repair welding of ductile cast iron by laser cladding process: microstructure and mechanical properties". International Journal of Cast Metals Research, 2014, v. 27 n 6.

CHIAVERINI, V. "Aços e ferros fundidos". $7^{\mathrm{a}}$ ed. São Paulo: Associação Brasileira de Metalurgia, Materiais e Mineração, p. 494, 2012.

DE PARIS, A. “Tecnologia da soldagem de ferros fundidos". Santa Maria: Editora UFSM, 2003, 140 páginas.

JUNIOR, E. M.; GUESSER, W. L. "Avaliação da usinabilidade do ferro fundido vermicular através de ensaios de furação". $6^{\circ}$ congresso brasileiro de engenharia de fabricação, 2011. 